\title{
Opinião
}

\section{PELO DIREITO DE TODOS A UM MEIO AMBIENTE SAUDÁVEL}

\author{
Hidemburgo Gonçalves Rocha (1) \\ Gilson Guilherme de Albuquerque Farias (2) \\ Geraldo João Pereira dos Santos(3)
}

Apesar do apelo dos órgãos governamentais e da própria mídia, as questões relacionadas ao cuidado ambiental ainda são um problema. Por um lado há os que se beneficiam da extração direta ou indireta dos recursos naturais, por outro, os que sofrem as conseqüências das ações danosas desta atividade.

Quando lidamos com meio ambiente, parece haver uma errônea noção de “propriedade”. Neste sentido, qualquer ação irresponsável pode causar danos irreparáveis a toda uma comunidade. Ainda que os riscos e danos ambientais atinjam a todos, o fato é que aqueles mais vulneráveis socialmente é que estão mais sujeitos a eles. Daí a necessidade de elementos reguladores destes processos.

Infelizmente, apesar dos avanços em termos educacionais e tecnológicos, ainda tem sido necessário fazer leis para coibir o desrespeito do homem com a natureza. Atitudes saudáveis para com o meio ambiente deveriam estar implícitas na consciência de cada um.

A legislação brasileira possui um conceito para Meio ambiente que está disposto no artigo $3^{\circ}$ da Lei $n^{\circ}: 6.938$ de 31 de agosto de 1981 sob a seguinte redação: "O conjunto de condições, leis, influências e interações de ordem física, química e biológica, que permite, abriga e rege a vida em todas as suas formas". O fato de haver uma proibição legal deveria implicar em um atendimento à mesma por todos os membros do conjunto social a ela submetidos, uma vez que as leis criam uma expectativa de ordem e organização, cujo foco deveria ser o interesse da coletividade. Afinal, espera-se contar com uma consciencia moral que promova o bem-estar de todos e garanta a outras gerações o mesmo grau de satisfação.

A maneira como as sociedades tem lidado com questões de Direito ambiental tem gerado inquietações sobre o nosso futuro, dadas as incertezas sobre o equilibrio natural. 
Segundo Trovão (2009), o valor da norma não está na lei propriamente dita, mas na sensação de plenitude, de igualdade, de satisfação completa e absoluta de um anseio comum a todos, de uma esperança que se vivifica através não apenas de um ordenamento jurídico organizado, mas sim, e principalmente, através de uma sociedade organizada e consciente de suas necessidades, de suas disponibilidades e também de sua interação uns com os outros. Esse valor ultrapassa os limites do interesse individual, lembrando-nos que somos seres vivendo em relação. Nenhum indivíduo vive sozinho, todos dependem de todos.

O direito ambiental tras essas assertivas com maior ênfase, e têm por finalidade a conservação, não apenas de um patrimônio que é comum a todos, mas a conservação da própria existência humana. Trata-se de uma questão de sobrevivência em que todos se beneficiam ao mesmo tempo em que são os próprios responsáveis.

Os primeiros movimentos aconteceram no final dos anos sessenta e início dos anos setenta e, trouxeram a tona discussões que, na época, encontravam-se restritas aos ambientes acadêmicos, principalmente das universidades americanas e européias, onde cada vez mais os recursos naturais estavam e estão escasseando, tornando a cada momento mais difícil a possibilidade e viabilidade da existencia humana (AB'SABER, 1984).

Sobre a necessidade de conservação do meio ambiente, James Lovelock (1979), cujas pesquisas revelaram uma teoria surpreendente sobre um suposto mecanismo autoregulador do planeta terra, publicou em 1979 algumas de suas idéias no livro "Gaia: A New Look at Life on Earth" no qual foi postulada de maneira mais definitiva a Hipótese Gaia. Segundo o autor, as condições químicas e físicas da superfície da Terra, da atmosfera, e dos oceanos tem sido, e continuam a ser, auto-ajustadas para criar condições confortáveis para a presença de vida. Isto se coloca em sentido oposto ao saber convencional que considera ocorrer o contrário, que a vida se adaptou as condições de vida planetárias existentes na Terra.

$\mathrm{O}$ autor também relata que todas as formas de vida na terra podem ser vistas como partes constitutivas de uma entidade única, um todo capaz de manter a composição da atmosfera da Terra adequada a suas necesidades. Gaia, seria então um ente complexo que inclui a biosfera terrestre, atmosfera, oceanos, e solo, e essa totalidade estabelece um mecanismo auto-regulador de sistemas cibernéticos, com a finalidade de procurar um ambiente físico e químico ótimo para a vida no planeta. $\mathrm{Na}$ mitologia clássica Gaia personificava a origem do mundo, o triunfo e ordenamento do cosmos frente ao caos, a protetora da fecundidade colocando-nos em direta sujeição à necessidade de preservação do meio ambiente como motivo fundamental para a sobrevivencia humana (LOVERLOCK, 1990). 
Esta interesante teoría de Lovelock nos mostra a inquietante questão do meio ambiente como elemento fundamental para a sobrevivência do ser humano no planeta. Aliás, a permanência e perpetuação significam a essência do fator biológico pelo qual é da natureza de cada espécie, nascer, crescer, reproduzir-se, e, morrer, razão pela qual o meio ambiente possui grande influencia.

\section{O Meio ambiente saudável como um direito}

A importância da conservação ambiental, quando a pensamos em termos de uma abordagem sistémica, centra-se na regulação das interações entre indivíduos e o meio ambiente, com a finalidade única e exclusiva de estabelecer a conservação de uma, em favor da preservação do outro.

Isso posto, enfatizamos o direito, enquanto ciência reguladora das relações para, à partir de um conjunto de leis e normas, encontrar-se uma maneira de lidar com este problema, aparentemente sem solução. Observe-se que extrair recursos do meio ambiente é a única forma que conhecemos de satisfazer nossas necessidades básicas de sobrevivência.

Ultimamente, a conservação do meio ambiente passou a representar uma questão primordial para que o homem possa pensar em termos de sua permanencia no planeta. Destruição de florestas e matas para a extração descontrolada de recursos, tornou-se alvo de questionamentos do direito coletivo, isto é do direito da própria humanidade que precisa ser protegida e preservada através do uso coerenre dos recursos naturais.

Neste sentido, uma consciência ambiental torna-se um elemento útil e necessário para a sobrevivência da raça humana. Senão vejamos. O conjunto de leis atualmente em vigor sobre meio ambiente constitui um arcabouço de caráter protetivo e sancionatário com vistas a assegurar, proteger e punir eventuais danos ambientais, considerando-se aqueles danos cujos resultados verificar-se-ão danosos coletividade.

O direito ambiental possui um conjunto de principios lógicos que estabelece seus limites de diretrizes, como forma de integrar-lhe um conjunto normativo devidamente estruturado e racionalmente instruído, e cujas orientações vão representar os valores que deverão ser protegidos com vistas à preservação de um bem comum. Um destes princípios - chamado de "princípio da precaução" - consagrado pela Declaração do Rio de Janeiro, constitui o seu enunciado $\mathrm{n}^{\circ} .15$ e tem a seguinte redação: 
Para proteger o meio ambiente, medidas de precaução devem ser largamente aplicadas pelos Estados, segundo suas capacidades. Em caso de risco de danos graves ou irreversíveis, a ausência de certeza científica absoluta não deve servir de pretexto para procrastinar a adoção de medidas efetivas visando prevenir a degradação do meio ambiente. (DECLARAÇÃO DO RIO DE JANEIRO, 1992).

Essa alegação não deixa claro o que seja "certeza científica". Isso minimiza os efeitos do princípio adotado, dificultando a efetiva proteção ao indivíduo - alvo direto do que deveria ser a proteção estabelecida.

Ao que parece, um conjunto de leis e pressupostos de direito não são suficientes para garantir e assegurar que as devastações ambientais e demais eventos de caráter destrutivo não mais tornarão a ocorrer, ou que as diversas populações possuam o necessário comprometimento com a sua efetiva consecução.

O estabelecimento de uma política de meio ambiente, a construção de um conjunto regulador das atividades econômicas auto-sustentáveis e a conseqüente aplicação de um sistema sancionador capaz e eficiente por si mesmo não apenas de punir, mas também prevenir eventuais danos, não constituem o mínimo necessário para que se estabeleça uma consciência ecológica. Isso é, o conjunto legislativo-jurídico não pode existir apenas por si próprio, alimentando-se de sua própria origem, sem se preocupar com a importância da formação de uma consciência que evoque uma verdadeira preocupação por parte de cada um, não apenas consigo próprio, mas a preocupação com a preservação, conservação e manutenção do meio ambiente, única forma de saber-se que, aquilo que nos serve hoje deverá também servir aos nossos filhos e netos assim como também aos nossos semelhantes.

\section{Referências:}

AB'SABER, Aziz N. Ecossistemas Continentais. Rqma - Relatório da qualidade do meio ambiente - SEMA, Brasília, 1984.

BRASIL. Lei $n^{\circ}$ 6.938, de 31 de agosto de 1981. Dispõe sobre a Política Nacional do Meio Ambiente, seus fins e mecanismos de formulação e aplicação, e dá outras providencias. Diário Oficial [da] República Federativa do Brasil, Brasília, DF, 02 set.1981. 
DECLARAÇÃO DO RIO DE JANEIRO. Estud. av., São Paulo, v. 6, n. 15, Ago. 1992 . In. $<$ http://www.scielo.br/scielo.php?script=sci_arttext\&pid=S010340141992000200013\&lng=en\&nrm=iso>. Accesso em 24 Nov. 2009. doi: 10.1590/S0103-40141992000200013.

LOVELOCK, J. E. Gaia - um modelo para a dinâmica planetária e celular. Em W. I.

Thompson (org.), Gaia — uma teoria do conhecimento. São Paulo, Editora Gaia, pp. 77-90, 1990.

LOVELOCK, J. E. Gaia- um novo olhar sobre a vida na Terra. Lisboa, Edições 70, 1989.

TROVÃO, A. de J. Direito Ambiental consciência ecológica e algumas verdades indizíveis. In: http:/br.monografias.com/trabalhos906/direito-ambiental/direito-ambiental.shtml. Acesso em 01/11/2009.

Sobre os autores:

(1) Hidemburgo Gonçalves Rocha é Professor Adjunto da Universidade Regional do Cariri e da Universidade Federal do Ceará, atuando na Faculdade de Medicina do Cariri.

E_mail: hidemburgo.rocha@bol.com.br.

(2) Gilson Guilherme de Albuquerque Farias é Engenheiro Florestal pela Universidade Federal Rural de Pernambuco e Mestre em Desenvolvimento Regional.

E_mail: gilson610@hotmail.com.

(3) Geraldo João Pereira dos Santos é Advogado pela Associação de Ensino Superior de Olinda - AESO. E-mail: geraldopsantos@nassau.com.br

\section{Como citar este artigo (Formato ISO):}

ROCHA, Hidemburgo G.; FARIAS, Gilson G. A.; SANTOS, Geraldo J.P. Reflexões acerca do direito de todos a um meio ambiente saudável. Id on Line Revista de Psicologia, Novembro de 2009, vol.1, no.10, p.16-20. ISSN 1981-1189. 